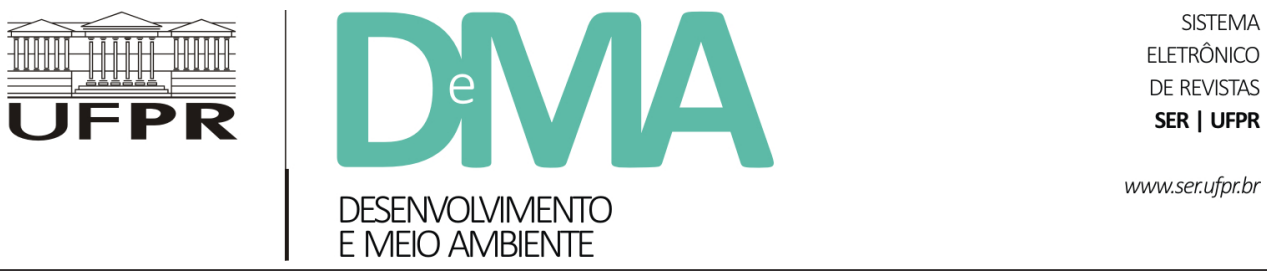

\title{
Análise da percepção do risco de desastres naturais por meio da expressão gráfica de estudantes do Projeto Defesa Civil na Escola
}

\section{Analysis of the Perception of Natural Disaster Risk Through Graphic Expression by Students in the Project "Civil Defense at School"}

\author{
Jefferson RIBEIRO ${ }^{1 *}$, Rafaela VIEIRA ${ }^{1}$, Daniela TÔMIO ${ }^{1}$ \\ ${ }^{1}$ Fundação Universidade Regional de Blumenau (FURB), Blumenau, SC, Brasil. \\ *E-mail de contato: jeff.r.bio@gmail.com
}

Artigo recebido em 8 de abril de 2016, versão final aceita em 31 de outubro de 2017.

\begin{abstract}
RESUMO: Os desastres naturais são cada vez mais frequentes no cotidiano da população mundial. Nos últimos anos, nenhum continente foi poupado de eventos naturais adversos que resultaram em desastres com consequências também para a vida humana. Em um contexto local, investigou-se uma ação de educação ambiental promovida pela Defesa Civil da cidade de Blumenau/SC/BR, denominada Defesa Civil na Escola. Objetivou-se identificar a percepção dos riscos de desastres naturais dos estudantes participantes do projeto, por meio de sua expressão gráfica. Para tal fim, foram realizadas uma pesquisa exploratória e uma análise documental das representações gráficas, na forma de desenhos, elaboradas por estudantes participantes do projeto. Para o tratamento e a análise dos desenhos, foi construída uma matriz contendo as categorias e os conteúdos empregados durante os encontros nas escolas e foi aplicado o método estatístico não paramétrico Qui-Quadrado. Os resultados indicaram que as práticas educacionais realizadas pela Defesa Civil Municipal são ferramentas importantes para mediar conteúdos relacionados à temática desastre natural. Além disso, essas práticas proporcionam aos estudantes do ensino fundamental uma visão complexa dos principais riscos de desastres existentes no município, capacitando-os a identificar seus principais impactos negativos, e os tornam disseminadores dessas informações, favorecendo o desenvolvimento de uma cidade resiliente em relação aos riscos de desastres naturais.
\end{abstract}

Palavras-chave: desastres naturais; educação ambiental; escola; percepção de risco.

ABSTRACT: Natural disasters are becoming more frequent in our daily life. In recent years, no continent has been spared from adverse natural events that have resulted in disasters with consequences for human life as well. In a local context, an environmental education project called "Civil Defense at School", promoted by the Civil Defense 
of the municipality of Blumenau/SC/BR, was investigated. This study aimed to identify, through graphic expressions, the perception of natural disaster risks that the participating students had. For this purpose, an exploratory research and a documental analysis of the graphic representations, which were the students' drawings, were held. For the treatment and the analysis of the drawings, an array containing the categories and the content employed during the school meetings was elaborated and the nonparametric Chi-Square statistical method was applied. The results indicated that the educational practices carried out by the Civil Defense of the municipality are important tools to mediate content related to the theme of natural disasters. These practices provide students of elementary school a complex vision of the main risks of the existing disasters in the city, enabling them to identify their main negative impacts. Also, they transform the students into disseminators of this information, favoring the development of a city that is resilient to the risks of natural disasters.

Keywords: natural disasters; environmental education; school; risk perception.

\section{Introdução}

Os desastres naturais são cada vez mais frequentes no cotidiano da população mundial. Nos últimos anos, nenhum continente foi poupado de eventos naturais adversos que resultaram em desastres naturais com consequências também para a vida humana.

No mundo, durante o período de 1 de julho de 2013 a 30 de junho de 2014, mais de 16.300 pessoas morreram e 113 milhões foram afetadas pelos 358 desastres internacionalmente relatados. O desastre mais mortal foi o tufão Haiyan, que devastou algumas ilhas das Filipinas e resultou em 7.354 mortes e pessoas desaparecidas (UNISDR, 2014).

O Brasil tem um longo histórico de desastres naturais. De acordo com o Atlas Brasileiro de Desastres Naturais (CEPED/UFSC, 2013), o país registrou, de 1991 a 2012, 38.996 ocorrências, com aumento significativo nos últimos anos. Segundo Tominaga et al. (2009), apesar de o país estar livre de fenômenos naturais, como terremotos e vulcões, existe um registro expressivo de eventos associados principalmente a estiagens, secas, escorregamentos e inundações, os quais proporcionam prejuízos e perdas significativas, inclusive de vidas humanas.

De acordo com Moura \& Silva (2008), os eventos naturais somente se convertem em desastres quando atingem seres humanos. Essa relação está sempre associada a danos, que ultrapassam a esfera econômica e interrompem a continuidade do funcionamento normal da sociedade, atingindo diretamente a qualidade de vida da população, especialmente nas cidades.

A ONU (2012) descreve a ação Cidades Resilientes, criada a partir do marco de ação de "Hyogo 2005-2015: construindo a resiliência das nações e comunidades frente aos desastres". Essa campanha estabelece dez passos com atividades críticas e interdependentes e visa ao cumprimento destes pelos poderes públicos locais, a fim de tornar suas cidades mais resilientes aos desastres ${ }^{1}$. Entre as medidas

\footnotetext{
1 "A campanha define "Cidade Resiliente" como sendo aquela que tem capacidade de resistir, absorver e se recuperar de forma eficiente os efeitos de um desastre e, de maneira organizada, prevenir que vidas e bens sejam perdidos. Uma das finalidades da campanha é mostrar que a redução de riscos e desastres ajuda na diminuição da pobreza, favorece a geração de empregos, de oportunidades comerciais e a igualdade social, além de garantir ecossistemas mais equilibrados e melhorias nas políticas de saúde e educação" (Brasil, 2015).
} 
estão aquelas que são objeto de interesse desta pesquisa, como "a criação de programas educativos e de capacitação em escolas e comunidades locais [...] e o estabelecimento de mecanismos de organização e coordenação de ações com base na participação de comunidades e sociedade civil organizada" (Brasil, 2015). Ao relacionarmos essas medidas com práticas efetivas nas cidades, destacamos para socialização uma das experiências realizadas pela Defesa Civil de Blumenau/SC/BR, membro do Projeto Cidades Resilientes.

O Programa Defesa Civil na Escola, desenvolvido na cidade, atua anualmente, desde o ano de 2013, em dez unidades escolares de Blumenau, com um projeto de educação ambiental cujo foco são medidas de prevenção de desastres naturais. Tal ação concretiza as exigências estabelecidas pela PNPDEC, que alterou a Lei n. 9.394/1996, a qual estabelece as Diretrizes e Bases da Educação Nacional, incluindo os princípios da proteção e da Defesa Civil e a educação ambiental como conteúdos obrigatórios nos currículos da Educação Básica (Brasil, 2012).

Os estudantes participantes do projeto vivenciam atividades com palestras, leituras, dinâmicas, vídeos, entre outras, durante três encontros e, ao final do último dia, a Defesa Civil avalia o desenvolvimento das aprendizagens com uma tarefa individual, que consiste em desenhar duas situações, uma com e outra sem a presença de risco, ou, se o aluno preferir, em escolher apenas uma das duas situações.

Esses desenhos encontram-se arquivados na Defesa Civil, mas não se tem utilizado ferramentas descritivas para identificar a percepção de riscos de desastres dos estudantes participantes. Pressupomos que tal descrição indicaria se as atividades estão desempenhando o papel esperado no desenvolvimento de uma cultura de prevenção de riscos de desastres, a qual é de competência da União, dos estados e dos municípios, segundo a Política Nacional de Proteção e Defesa Civil (PNPDEC), como também possibilitaria avaliar as ações e buscar, se necessário, melhorias na intervenção nas escolas.

Dessa forma, conseguir diagnosticar se as práticas educacionais empregadas pelo órgão público estão conseguindo sensibilizar e construir uma cultura de prevenção de riscos de desastres naturais, com base na percepção destes pelos estudantes, torna-se algo necessário para a consolidação dessa ação de educação ambiental local. Além disso, constitui-se em uma possibilidade de compartilhar a experiência com outros municípios onde os desastres naturais são recorrentes, a fim de contribuir para a campanha das cidades resilientes.

Diante desse contexto, realizou-se uma pesquisa com o objetivo de identificar a percepção dos riscos de desastres naturais dos estudantes participantes do Projeto Defesa Civil na Escola por meio da expressão gráfica, a fim de avaliar a contribuição que órgão público de Defesa Civil vem promovendo nas capacitações realizadas nas escolas do município de Blumenau. Entende-se que a escola é um alicerce na construção do pensamento crítico de sua sociedade e, ao ser parceira da Defesa Civil, pode ampliar a sua função social, propiciando aos estudantes - e, por extensão, às suas comunidades - possibilidades para construção de novas relações sustentáveis no ambiente sociocultural com base no desenvolvimento de uma percepção acerca dos riscos de desastres relacionados a eventos naturais extremos.

Admitindo-se a existência de percepções individuais e coletivas, entende-se que a percepção de 
risco constitui-se em uma construção social e é, portanto, uma representação mental vinculada à cultura existente (Renn, 1998; Guivant, 1998). Para Renn (2008), é possível compreender a percepção de risco como o processamento de sinais físicos ou informações sobre eventos, atividades potencialmente perigosas e a formação de julgamento com base na seriedade, na probabilidade e na aceitabilidade de um respectivo evento ou atividade. Segundo Burton \& Kates (1972), as pessoas com mais experiências prévias com desastres e que tiveram relação mais econômica com estes tendem a perceber os riscos como problema.

A estrutura do presente artigo está organizada em quatro seções. Inicialmente, abordamos referências que nos permitem compreender aspectos da educação ambiental (EA) para a redução de riscos de desastres (RRD). Na sequência, é descrito o percurso investigativo situando o contexto investigado, os participantes, os métodos de coleta e de análise dos dados. Por conseguinte, são abordadas as interpretações dos resultados, considerando uma análise estatística dos dados observados. Por fim, são feitas as considerações finais resultantes da pesquisa.

\section{Aspectos da educação ambiental (EA) para redução de riscos de desastres (RRD)}

De acordo com o relatório do Escritório das Nações Unidas para a Redução do Risco de Desastres (UNISDR, 2014), a necessidade de minimizar os impactos de riscos futuros de desastres naturais é algo fundamental para as comunidades em todo o mundo. Reduzir os níveis existentes de riscos que favorecem os desastres, fortalecendo a resiliência social, ambiental e econômica, é uma das soluções encontradas para que as cidades consigam conviver com esses fenômenos naturais.

Segundo Rodrigues (2010), com a crescente preocupação internacional em relação ao aumento dos desastres naturais, as Nações Unidas (ONU) realizaram uma assembleia no ano de 1989 para aprovar a Resolução 44/236, que estabelece a década de 1990 como a Década Internacional para a Redução de Desastres Naturais (DIRDN). No ano de 1994, ocorreu a $1^{\text {a }}$ Conferência Mundial sobre a prevenção dos desastres naturais, que resultou na apresentação da Estratégia e do Plano de Ação de Yokohama, primeira iniciativa de elaboração de um plano de redução de desastres com orientações sociais comunitárias.

Ao final da referida década, as Nações Unidas criaram um secretariado definitivo em Genebra, impulsionando a Estratégia Internacional para Redução de Desastres (EIRD), com a função de promover, por meio do desenvolvimento sustentável, maior consciência da aplicação da redução de desastres, desenvolvendo comunidades resilientes a eventos naturais (Rodrigues, 2010).

Em 2005, durante a segunda Conferência Mundial de Redução de Riscos de Desastres da ONU, foi aprovado o Marco de Ação de Hyogo $(\mathrm{MAH})$, e a redução do risco definitivamente passou a circular como prioridade estratégica no enfrentamento de desastres (Santos, 2015). O MAH foi um instrumento importante para aumentar a resiliência das nações e das comunidades em relação aos desastres, o qual visava alcançar, até o ano de 2015, redução considerável das perdas ocasionadas por esses eventos, tanto em relação às vidas humanas quanto aos bens econômicos, sociais e ambientais dos países (EIRD ONU, 2007). 
No ano de 2015, foi desenvolvido em Sendai, Japão, o novo protocolo de ação das Nações Unidas para a RRD, que substituiu o MAH. O documento foi ratificado pelos representantes de 187 países, reunidos na $3^{\text {a }}$ Conferência Mundial de Redução de Riscos de Desastres (Santos, 2015).

O Marco de Sendai articula-se por meio de propostas, como melhorar a compreensão de risco de desastres em todas as suas dimensões de exposição, promover o fortalecimento da governança de risco de desastres, incluindo plataformas nacionais, prestando contas para a gestão de risco de desastres e promovendo a resiliência das infraestruturas (UNISDR, 2015a).

Segundo a nota informativa sobre a $21^{\mathrm{a}}$ Paris Climate Conference (COP21), as perdas e os danos associados às alterações climáticas estão aumentando e deixando suas marcas em países desenvolvidos e em desenvolvimento em todo o mundo (UNISDR 2015b). Diante desse cenário de mudanças climáticas, a educação ambiental, especialmente nas escolas, torna-se cada vez mais importante na formação de uma sociedade sustentável.

Art. $2^{\circ}$. A Educação Ambiental é uma dimensão da educação, é atividade intencional da prática social, que deve imprimir ao desenvolvimento individual um caráter social em sua relação com a natureza e com os outros seres humanos, visando potencializar essa atividade humana com a finalidade de torná-la plena de prática social e de ética ambiental. (Brasil, Resolução n. 2, de 15 de junho de 2012)

Em um cenário complexo, de um mundo globalizado acometido por problemas relevantes como as mudanças climáticas, a educação ambiental deve desenvolver teorias e práticas a fim de ser crítica, emancipatória e transformadora, construindo diver- sos conhecimentos, valores, habilidades e atitudes ao preparar as pessoas para a efetiva formulação de seus destinos (Brasil, 2009). Por estes motivos as questões ambientais tornam-se cada vez mais presentes na sociedade e demostram ser essenciais em todos os níveis dos processos educativos, especialmente nos anos iniciais da escolarização, uma vez que se torna mais fácil sensibilizar crianças em relação às questões ambientais que os próprios adultos (Medeiros et al., 2011).

De acordo com Silva (2011), a educação ambiental tornou-se uma evidência, impondo-se como necessidade nas instituições e produzindo, por consequência, a geração de consensos na sociedade, como o bordão já bem estabelecido pela convocação de que devemos "salvar o planeta". Para os autores Marques et al. (2014), a educação ambiental proporciona um exercício da cidadania em que todos os componentes da sociedade devem ser participantes desse processo educacional.

Vivemos em uma era de grande dilatação do conhecimento científico e de suas aplicações, de modo que se torna essencial o fortalecimento do debate público, nos diferentes níveis, relacionados ao papel ocupado pela ciência, para a sustentabilidade do planeta (Pian \& Alves, 2013). Atualmente, a existência de uma matriz curricular voltada para a redução de risco de desastres ainda está limitada a explorar a ciência básica de riscos ambientais, antes de passar à instrução sobre medidas de segurança. $\mathrm{O}$ que frequentemente falta é a cobertura sistemática do perigo, sua prevenção e sua mitigação, e a preparação para enfrentá-lo (UNESCO, 2012).

Oportunizar a compreensão da educação ambiental e incluir em sua competência a cultura de redução de riscos de desastres nos espaços escolares, ou seja, a capacidade de as pessoas conseguirem 
observar e compreender os riscos que as envolvem, tornam-se uma estratégia importante que pode ser vinculada utilizando uma ampla variedade de material pedagógico e didático de apoio (CEPED/ UFSC, 2012). Englobar essas dimensões proporciona maior profundidade, largura e infraestrutura para a compreensão dos princípios e o alcance da educação para a RRD (UNESCO, 2012).

As práticas educativas apontam para propostas pedagógicas correlacionadas na mudança de atitudes, hábitos e práticas sociais, proporcionando competências, capacidade de avaliação e participação dos estudantes. Nesse contexto, os educadores têm papel estratégico e incontestável na inserção da educação ambiental no âmbito escolar, construindo com os educandos um posicionamento crítico perante a crise socioambiental existente (Jacobi, 2005).

Para superar ameaças futuras, a sociedade deve estar preparada, desenvolvendo ferramentas para amenizar os impactos que serão causados após a ocorrência dos desastres naturais e partindo da prevenção, de modo a evitar que o desastre ocorra. Para Narváez et al. (2009), existem provas de que na América Latina, ao se reduzir o risco existente exclusivamente por meio da mitigação, ou seja, estabelecendo-se medidas corretivas e de controle, há a demonstração, em muitos casos, de resultados inseguros. Deve-se, sim, evitar o risco futuro, utilizando medidas de prevenção dos fatores de risco, antes de sua consolidação em potencial desastre. Essa é ainda uma das alternativas mais aplicáveis.

Nessa direção, em parceria com a escola, as Diretrizes Curriculares Nacionais para Educação Ambiental preveem:

e) trabalho de comissões, grupos ou outras formas de atuação coletiva favoráveis à promoção de educação entre pares, para participação no planejamento, execução, avaliação e gestão de projetos de intervenção e ações de sustentabilidade socioambiental na instituição educacional e na comunidade, com foco na prevenção de riscos, na proteção e preservação do meio ambiente e da saúde humana e na construção de sociedades sustentáveis. (Brasil, Resolução n. 2, de 15 de junho de 2012, grifo nosso)

Entre essas formas de atuação coletiva, destaca-se nesta pesquisa a Defesa Civil. De acordo com o artigo $3^{\circ}$ da PNPDEC - Lei n. 12.608/2012 -, as ações de prevenção, mitigação, preparação, resposta e recuperação relacionadas à proteção e à defesa civil devem estar inseridas às políticas que se interligam com o desenvolvimento urbano, o ordenamento territorial, o meio ambiente, a saúde, a gestão de recursos hídricos, as mudanças climáticas e também a educação, além das demais políticas setoriais, tendo como meta a promoção do desenvolvimento sustentável (Brasil, 2012). Uma compreensão acerca de um trabalho que envolva essas dimensões na relação Defesa Civil e escola é detalhado na sequência.

\section{Percurso investigativo}

\subsection{Caracterização do contexto de estudo}

O município de Blumenau, localizado em Santa Catarina (Figura 1), compreende uma área de $519,8 \mathrm{~km}^{2}$. Sua população era de 309.011 habitantes em 2010, com taxa de crescimento de 1,67\% ao ano, de 2000 a 2010 (IBGE, 2010). O munícipio está inserido no bioma Mata Atlântica e apresenta vasta riqueza de espécies vegetais e animais. 
Sua história conta com uma colonização predominantemente de origem germânica, que teve grande influência na cultura blumenauense e impulsionou seu desenvolvimento econômico. Atualmente, a cidade possui 87 escolas de ensino fundamental, públicas e privadas, com mais de 38.839 matrículas realizadas no ano de 2012 (IBGE, 2010).

Blumenau localiza-se na bacia hidrográfica do Rio Itajaí (BHRI), que apresenta registros recorrentes de desastres naturais, especialmente inundações, enxurradas e movimentos gravitacionais de massa ou deslizamentos. A BHRI apresenta uma área total aproximada de $15.000 \mathrm{~km}^{2}$, o que corresponde a $16,15 \%$ do território catarinense e a $0,6 \%$ do território brasileiro (Comitê do Itajaí, 2010).

Historicamente, as enchentes ocorridas nos anos de 1911, 1983 e 1984 impactaram em diversas esferas, prejudicando severamente áreas ambientais e principalmente a economia do município. De acordo com o estudo de Tachini et al. (2009, p. 14), "[...] os danos estimados para o ano de 1983 foram superiores a 77 milhões, representando um dano médio de $\mathrm{R} \$ 91,87$ por área construída residencial”. De 2008 a 2015, foram registradas nove enchentes de proporções relevantes para o município de Blumenau, causando impactos negativos em diversas áreas (Alertablu, 2015).

Além das inundações popularmente conhecidas na cidade, os deslizamentos, desastre natural pouco conhecido até 2008 , provocaram a morte de inúmeras pessoas (Hein et al., 2013). Assim como para as inundações, o agente deflagrador dos escorregamentos são as elevadas precipitações, que se tornaram evento físico danoso pelo fato de que as encostas passaram a ser densamente ocupadas.

Segundo Pinheiro \& Severo (2010), no evento de 2008, o volume pluviométrico apresentou longa duração e elevada intensidade. A precipitação durou seis dias contínuos, e a quantidade elevada de chuvas ultrapassou uma série histórica de 64 anos. Devido a essa grande quantidade de chuva, enxurradas, deslizamentos e inundações submeteram a BHRI a decretar estado de calamidade pública em 14 municípios, e outros 65 decretaram situação de emergência (Frank et al., 2009).

Por causa da grande quantidade de cidades atingidas, o desastre ocasionou perdas irreparáveis e, com isso, inúmeras foram as vidas perdidas, um evento que abalou a economia local, somando um prejuízo de mais de três bilhões de dólares (Hein et al., 2013). Diante desse cenário, historicamente a Defesa Civil de Blumenau, como órgão responsável pela coordenação da gestão de riscos de desastres, tem organizado com a comunidade ações de geração de conhecimento, prevenção, mitigação, preparação, resposta e reconstrução aos riscos de desastres. Segundo a Lei Complementar n. 870/2013, entre as competências do órgão, está estabelecer estratégias e diretrizes para orientar ações de prevenção e também de defesa permanente contra desastres naturais, integrando-se a todos os órgãos governamentais e não governamentais (Blumenau, 2013). Entre as competências municipais estabelecidas na PNPDEC, está o desenvolvimento de ações de educação ambiental, das quais o Programa Defesa Civil na Escola é o contexto desta investigação.

Esse projeto, desenvolvido desde o ano de 2013 pela Defesa Civil de Blumenau, é realizado em três encontros agendados previamente em cada uma das dez escolas públicas ou particulares participantes na edição anual. Durante os encontros, são abordados temas que preparam os estudantes para as situações de risco. No primeiro encontro, são esclarecidas as noções básicas de Defesa Civil. No 
segundo, o tema principal contempla a percepção de risco, e no terceiro finaliza-se com a temática desastres ambientais, demonstrando situações cotidianas da cidade. Durante os encontros são entregues aos estudantes os kits de cartilhas educativas desenvolvidas pela Secretaria de Defesa Civil do Estado de Santa Catarina, com foco em desastres naturais, da Série Nossa Segurança. O Projeto Defesa Civil na Escola conta com a parceria da Secretaria Municipal de Educação de Blumenau.

Durante os três anos de projeto (2013 a 2015), foram atendidos aproximadamente quatro mil estudantes nas 22 unidades escolares participantes no município de Blumenau. Essas escolas foram estrategicamente selecionadas pela Defesa Civil, principalmente por estarem localizadas em áreas atingidas por enchentes e ou deslizamentos (Figura $1)$.

Em 2013, a Escola Básica Municipal Visconde de Taunay e a Escola de Educação Básica Luiz Delfino foram as primeiras unidades a receber a iniciativa de educação ambiental desenvolvida pela Defesa Civil. Os estudantes do $6^{\circ}$ ao $9^{\circ}$ anos foram o público-alvo inicial do projeto. Essa primeira etapa foi o piloto do projeto, com base no qual foram estabelecidos os novos moldes para os anos seguintes.

Em 2014 e 2015, houve uma modificação no enfoque do projeto. O grupo de estudantes contemplados nos encontros de educação ambiental foram os estudantes do $4^{\circ}$ ano do ensino fundamental, em virtude do maior interesse desse grupo de estudantes pelas aulas aplicadas pela Defesa Civil. Além disso, o programa passou a atender dez escolas por ano.

\subsection{Procedimentos metodológicos}

A pesquisa tem caráter exploratório quanto ao seu objetivo e, em relação ao procedimento, trata-se de uma análise documental. Por documento entende-se, com base na definição de Appolinário (2009, p. 67), "qualquer suporte que contenha informação registrada, formando uma unidade, que possa servir para consulta, estudo ou prova. Incluem-se nesse universo os impressos, os manuscritos, os registros audiovisuais e sonoros, as imagens, entre

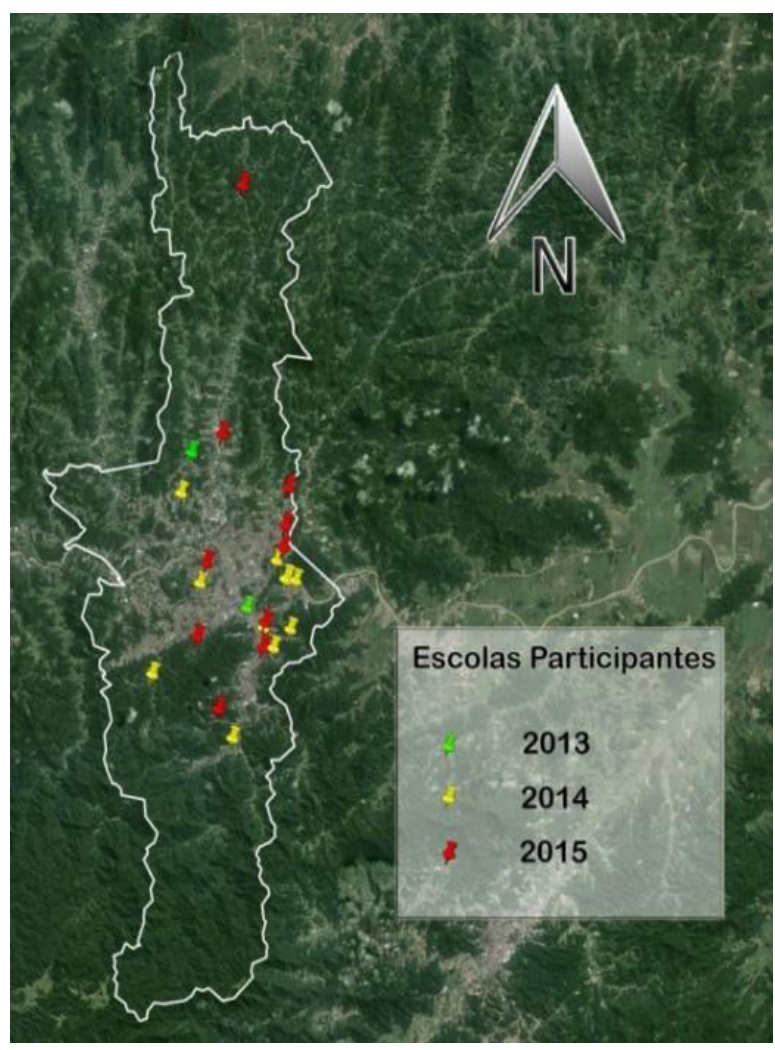

FIGURA 1 - Município de Blumenau, em destaque escolas atendidas pelo projeto.

FONTE: Google Maps, adaptação própria. 
outros". Nessa direção, evidenciamos os desenhos dos estudantes, aqui denominados "representações gráficas", como os documentos empregados para observação.

Os desenhos foram coletados na edição do ano de 2015 do Projeto Defesa Civil na Escola, devido à participação de um dos pesquisadores que, por meio de observação participante, acompanhou os encontros realizados nas escolas em conjunto com a equipe da Defesa Civil. Foram selecionados para a investigação os desenhos realizados no referido ano, os quais abordavam as duas situações: uma com e outra sem risco de desastre natural.

Pelo fato de o município de Blumenau ter sido atingido por uma inundação no dia 23 de outubro de 2015 de proporções consideráveis, perfazendo 10,03 m acima do nível normal do rio, durante a execução do projeto, três escolas não precisaram realizar os desenhos solicitados pela Defesa Civil, visto que as unidades escolares foram atingidas in-

TABELA 1 - Matriz de observação dos desenhos

\section{Módulos}

\section{Noções básicas de Defesa Civil}

Explica as informações básicas sobre o órgão público de Defesa Civil e suas respectivas competências.

\section{Conteúdos}

- Símbolo da Defesa Civil

- Telefone da Defesa Civil

- Nome da Defesa Civil

- Cores da Defesa Civil

- Ação entre várias pessoas

- Atividades desenvolvidas pelo órgão

- Cidades destruídas

- Alerta

- Nível do rio

- Abrigos de Defesa Civil

- Voluntários

\section{Percepção de Risco}

Esclarece aos estudantes importantes aspectos que ajudam a identificar possíveis situações que promovam riscos ambientais e à vida humana.
- Árvores inclinadas

- Ausência da vegetação

- Presença de bananeira

- Casa no morro

- Casa próximo ao morro

- Casa no plano

- Casa com calha

- Casa sem calha

- Presença de chuva

- Despejo de esgoto a céu aberto 
- Lixo espalhado

- Lixo organizado

- Solo exposto

- Rachaduras nas paredes

- Tubulação exposta

- Tubulação interna

- Entupimento de bueiro.

- Gramínea Vetiver

\section{Desastres}

Engloba os principais desastres da região e seus impactos na sociedade.

- Danos materiais

- Danos ambientais

- Remoção das pessoas das casas

- Casa desabando

- Inundação

- Deslizamento de solo

- Furacão

diretamente por essa ameaça, o que impossibilitou que o órgão público desenvolvesse essa atividade. Por esse fator, na pesquisa analisou-se sete escolas participantes do projeto.

Para identificar a percepção dos riscos de desastres naturais dos estudantes por meio dos elementos gráficos desenhados, foi elaborada a priori uma matriz para observação (Tabela 1). Sua proposição considerou principalmente os conteúdos abordados com os estudantes nas escolas, com base em diferentes metodologias, nos três módulos do projeto (noções básicas de defesa civil; percepção de risco e desastres). Esses conteúdos são importantes para os estudantes formularem suas explicações acerca de noções como as competências da Defesa Civil; as situações que promovem riscos ambientais e à vida humana e os principais desastres da sua região, bem como seus impactos na sociedade.
Com a matriz (Tabela 1), realizou-se a identificação quanto à presença ou ausência desses conteúdos nos desenhos dos estudantes. Os dados produzidos foram tabulados e posteriormente transformados em gráficos.

Para cada turma, foram identificados e descritos quais conteúdos eram mais evidentes nos desenhos de áreas seguras e de áreas com risco para ocupação humana. Um exemplo dessa observação foi ilustrado na Figura 2.

Para verificar a associação entre as frequências dos dados obtidos na análise dos desenhos, empregou-se o teste Qui-Quadrado de Aderência. Os testes foram aplicados com nível de significância de 5\% $(a=0,05)$. O Qui Quadrado trata-se de um teste de hipóteses que busca encontrar um valor da dispersão para duas variáveis nominais e, assim, possibilita avaliar a associação existente 


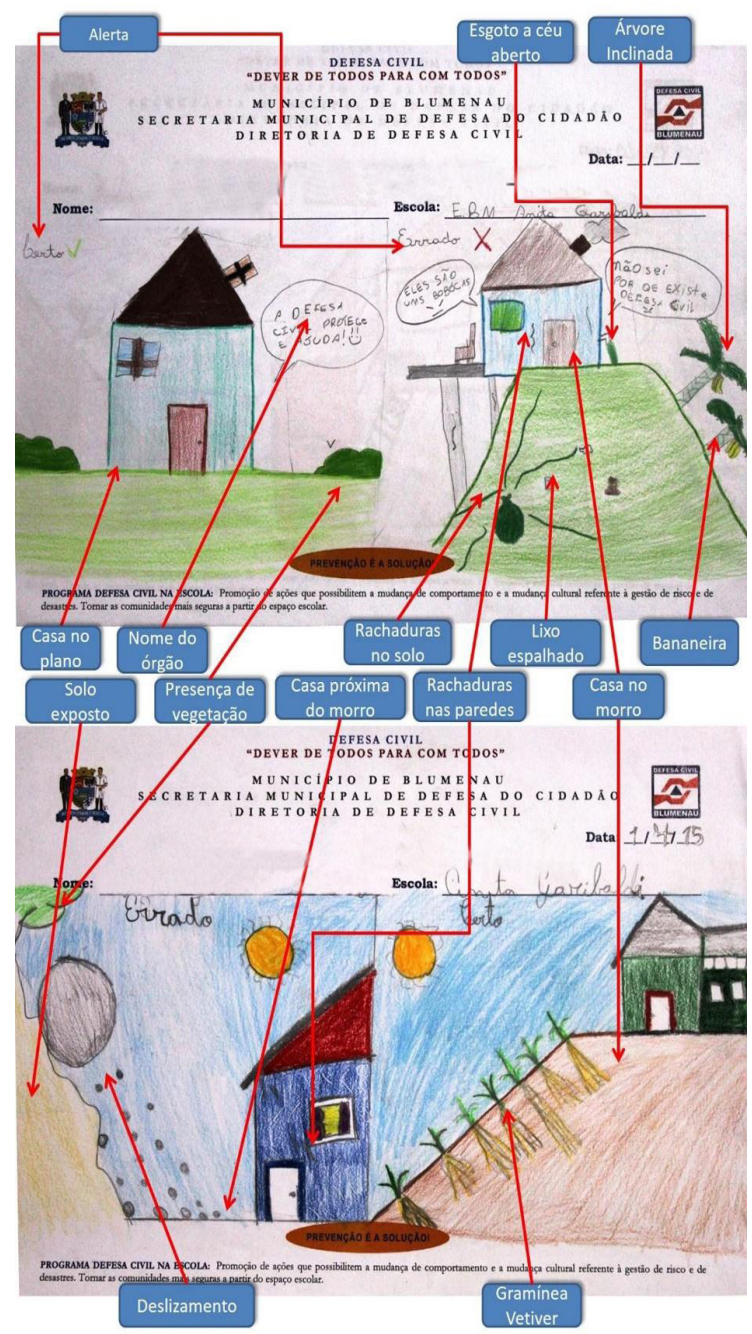

FIGURA 2 - Destaque para conteúdos avaliados nos desenhos FONTE: Desenhos de estudantes do programa Defesa Civil na Escola (2015).

entre variáveis qualitativas. Esse teste é utilizado para verificar se a frequência com que determinado acontecimento observado em uma amostra desvia ou não significativamente da frequência com que ele é esperado (UFPA, 2011). Com esse intuito, a técnica foi aplicada para comparar as principais diferenças significativas encontradas entre alguns conteúdos relevantes, que apresentaram maior discrepância no contexto geral entre os desenhos analisados.

\section{Resultados}

Aplicando as regras de triagem, nas quais foram selecionados somente os desenhos em que os estudantes da rede de ensino de Blumenau representaram as duas situações (área de riscos e área segura), foram avaliados 197 desenhos (Tabela 2). As porcentagens foram estabelecidas em relação à quantidade de desenhos analisada por unidade escolar. As variáveis dos três encontros estiveram presentes na maioria dos desenhos, especialmente as do segundo encontro, que aborda a percepção de risco.

Os aspectos mais evidentes demonstrados pelos estudantes referenciavam a ocupação das construções em morros, a prevalência de bananeiras em localidades inapropriadas e a grande presença da gramínea vetiver nas áreas com e sem risco. Outros fatores delimitados pelos estudantes foram o solo exposto e a presença de lixo espalhado pelos terrenos. A chuva esteve presente em número considerável de desenhos e, na maioria das vezes, esteve atrelada exclusivamente a áreas de risco. Entre os desenhos analisados, poucas foram as referências aos eventos de desastres naturais: apenas três apresentaram furacões, oito enfatizaram inundação e trinta referenciaram os deslizamentos.

$\mathrm{Na}$ avaliação dos encontros realizados pela Defesa Civil, diagnosticou-se que no primeiro encontro, em que são abordadas as noções básicas 
de Defesa Civil, dos 11 conteúdos abordados, os estudantes representaram 10 nos desenhos. Em ordem decrescente foram enfatizados os alertas, as cores, o nome e o telefone do órgão, com certa similaridade entre os desenhos de áreas seguras e inseguras (Figura 3).

Em quase todos os desenhos foram feitas pequenas menções que alertavam se a área tinha algum risco ou não. Em alguns casos, pequenos bonecos com balões de fala comunicavam a população sobre o perigo; em outros, os desenhos classificavam a área em segura ou inadequada. A única informação que não foi representada em nenhum desenho correspondeu à presença de voluntários.

O segundo encontro, que aborda a percepção de risco, foi o que apresentou maior quantidade de

TABELA 2 - Número de estudantes envolvidos e desenhos selecionados

\begin{tabular}{lcc}
\hline \multicolumn{1}{c}{ Unidade escolar } & Número de estudantes & Número de desenhos \\
\hline EBM Anita Garibaldi & 140 & 80 \\
Escola Barão do Rio Branco & 153 & 57 \\
EBM General Lucio Esteves & 84 & 23 \\
EBM Enrich Klabunde & 20 & 10 \\
EBM Hermam Hamann & 48 & 18 \\
EBM Henrique Alfarth & 40 & 05 \\
EBM Professora Helena M. N. Winckler & 22 & 04 \\
Total & 507 & 197 \\
\hline
\end{tabular}

\section{Noções básicas de Defesa Civil}

Voluntários

Abrigos de Defesa Civil

Nivel do rio

Alertas

Cidades destruidas

Açäo entre varias pessoas

Atividades desenvolvidas pelo órgäo

Cores da Defesa Civil

Nome da Defesa Civil

Telefone da Defesa Civil

Simbolo da Defesa Civil

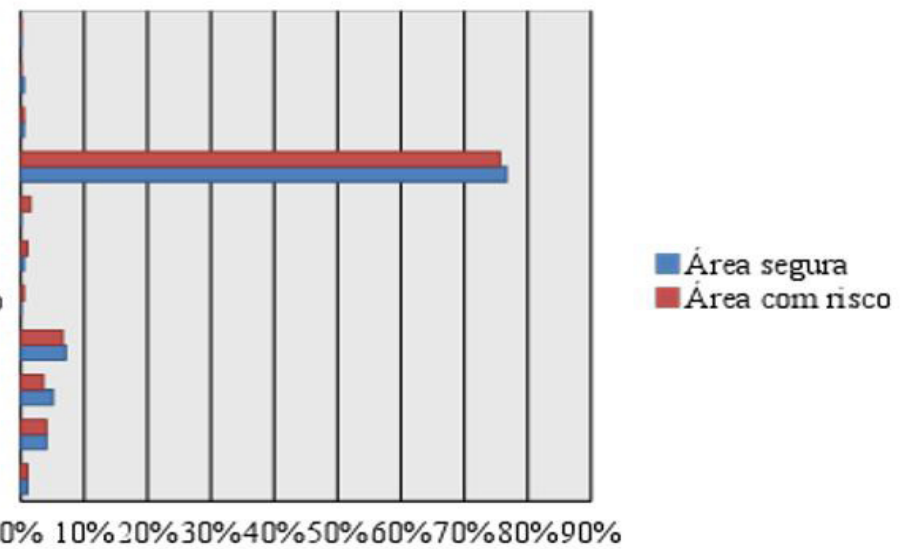

FIGURA 3 - Gráfico demonstrando a representatividades das variáveis do primeiro encontro 
conteúdos representados. Dos 18 conteúdos abordados no encontro, somente um não foi representado. Houve bastante diferença na representação de acordo com as situações de segurança e risco. Nas situações de segurança, os conteúdos com maior significância, em ordem decrescente, foram gramínea vetiver, casa sem calha, casa localizada no morro e solo exposto com a mesma quantidade, casa localizada no plano e casa com calha. Nas situações de risco, os conteúdos com maior representação, em ordem decrescente, foram casa sem calha, casa localizada no morro, solo exposto, presença de chuva, casa próxima ao morro e presença de bananeira.

Nas situações de risco, 70\% dos desenhos abordaram a presença da gramínea vetiver, espécie exótica introduzida no Brasil com a função de controlar o deslizamento em encostas. A planta foi representada em todas as formas de relevo, mesmo em terrenos planos (Figura 4).

O fato pelo qual apareceram muitos desenhos com essa gramínea tende a estar interligado com uma animação apresentada pela Defesa Civil, durante o segundo encontro. Esse recurso visual exemplifica a importância da gramínea na contenção de encosta.

De acordo com Clebsch \& Mors (2004), o uso perspicaz de trechos de filmes pode ser considerado um elemento motivador. Os estudantes atualmente estão inseridos em uma cultura em que a habilidade visual e a de processar informações são firmemente utilizadas e praticadas. Para Rosa (2000), a interação com equipamentos multimídia apresenta forte apelo emocional, ou seja, tais equipamentos funcionam como facilitadores nos processos de aprendizagem dos conteúdos propostos pelo mediador.

Contudo, apesar de tantos recursos facilitarem a obtenção e o acesso às informações, a presença do mediador é indispensável, visto que essas ferramentas não o substituem o professor em sala de aula. É com o auxílio do professor que o estudante é guiado a construir seu próprio conhecimento, utilizando como base as informações adicionais presentes no vídeo (Oliveira \& Dias, 2012).

Outro ponto importante observado nos desenhos está nas casas presentes em áreas planas e naquelas localizadas nos morros (Figura 4). Nas análises estatísticas, obteve-se que as frequências não são uniformes para a situação das casas localizadas nos morros em relação a áreas de riscos e áreas seguras. Isto é, existe uma divergência do nível de significância de 0,05 , sendo o valor de $\mathrm{P}=$ 0,001. Portanto, a hipótese nula, que demonstra que não há diferença na percepção dos estudantes para as situações de risco e de segurança, foi rejeitada.

Consequentemente, existe diferença significativa entre os desenhos que possuíam casas nos morros, na situação de risco, em comparação com os desenhos da área segura (Tabela 3). Foi observado que os estudantes desenharam em $63,6 \%$ dos desenhos casas em locais de morro considerando a área como perigosa. Essa mesma divergência nas frequências foi observada para as casas localizadas em locais planos ao comparar as áreas de risco e de segurança (Tabela 4). $\mathrm{O}$ valor foi de $\mathrm{P}=0,001$, confirmando que as frequências não são uniformes. Nesse caso, ficou explícito que as casas construídas em morros $(83,84 \%)$ estavam vinculadas a áreas de risco.

Essa diferença observada evidencia que, na percepção dos estudantes, de modo geral, uma casa localizada em áreas de relevo acidentado é mais suscetível aos desastres naturais que as casas localizadas em locais planos, e as casas localizadas em locais planos configuram áreas de segurança. 


\section{Percepção de risco}

Graminea V etiver

Entupimento de Bueiro

Tubulação Interna

Tubulação exposta

Rachachuras no Solo

Rachachuras nas paredes

Solo Exposto

Lixo Organizado

Lixo Espalhado

Despejo de esgoto a céu aberto

Presença de Chuva

Casa sem calha

Casa com calha

Casa no plano

Casa próximo ao morro

Casa no morro

Bananeira - Planta

Ausência da vegetação

Árvores inclinadas

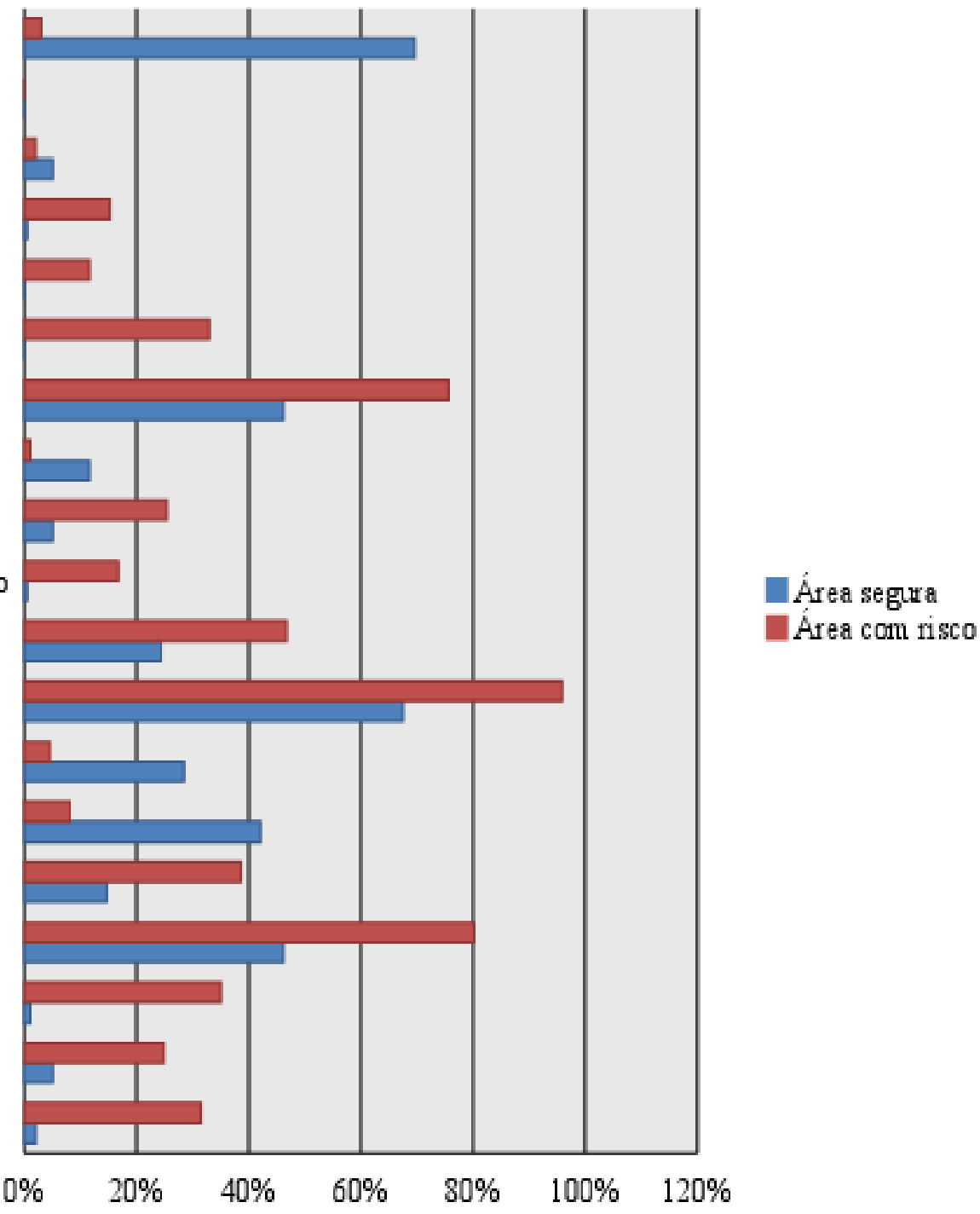

FIGURA 4 - Gráfico demonstrando a representatividade das variáveis do segundo encontro 
TABELA 3 - Frequências absoluta e relativa da presença de construções em regiões de morros, em: 1 - área com risco e 2 -área segura

\begin{tabular}{cccc}
\hline \multirow{2}{*}{ Categorias } & \multicolumn{2}{c}{ Frequências } & Qui-Quadrado \\
\cline { 2 - 4 } & Absoluta (N) & $\begin{array}{c}\text { Relativa } \\
(\%)\end{array}$ & (p-valor) \\
\hline 1 & 159 & 63,60 & $<0,001$ \\
2 & 91 & 36,40 & \\
\hline Total & 250 & 100 & \\
\hline
\end{tabular}

TABELA 4 - Frequências absoluta e relativa da presença de construções em regiões planas, em: 1 - área com risco e 2 - área segura

\begin{tabular}{cccc}
\hline \multirow{2}{*}{ Categorias } & \multicolumn{2}{c}{ Frequências } & Qui-Quadrado \\
\cline { 2 - 4 } & Absoluta (N) & $\begin{array}{c}\text { Relativa } \\
(\%)\end{array}$ & (p-valor) \\
\hline 1 & 16 & 83,84 & $<0,001$ \\
2 & 83 & 16,16 & \\
\hline Total & 99 & 100 & \\
\hline
\end{tabular}

Nos desenhos de áreas com risco, praticamente em todas as escolas houve presença maior das casas localizadas nos morros, evidenciadas nas análises estatísticas. A EBM Lucio Esteves, escola localizada em uma área plana e livre de deslizamentos, apresentou, em todos os desenhos analisados (100\%), casas construídas em morros (Figura 5). Essa percepção de perigo atrelada ao local onde a construção foi realizada tende a estar relacionada com os exemplos que a Defesa Civil de Blumenau utiliza durante o encontro, os quais enfatizam a problemática de construir casas em áreas de risco. No decorrer das aulas, são mostrados fotos e vídeos de casas localizadas em encostas.

De modo geral, os desenhos de situação sem risco apresentaram certa semelhança entre a presença de casas nos morros e em áreas planas. Contudo, muitos desenhos associavam as casas nos morros com a gramínea vetiver, indicando que a localidade encontrava-se segura para a ocupação.

Houve alguns casos especiais, como a EBM Lucio Esteves, na qual 74\% dos desenhos apresentaram casas em morros (Figura 6). Essa unidade escolar está inserida em uma localidade extremamente plana e com poucas morrarias em seu entorno. Apesar do elevado número de construções em locais passíveis de desastre, em todos os desenhos, os estudantes também representam o vetiver como possível solução para contrapor os riscos de desastres. Em nenhum dos desenhos foram evidenciadas rachaduras nas paredes ou deslocamento de solo, corroborando a estabilidade da localidade proposta pelo estudante.

Entre todas as unidades escolares, destaca-se o elevado percentual de casas representadas sem calha. Nas áreas de risco, observa-se essa ausência em 96\% das casas. Contudo, nas situações de segurança, o valor continuou elevado, com $68 \%$ dos desenhos, mas demonstrou considerável redução entre a área de risco (Figura 4). Entende-se que a baixa evidência na representação da calha pode estar relacionada com a falta de detalhes apresentada pelos estudantes em seus desenhos, pois a maioria dos estudantes nesta idade não estão acostumados a desenhar objetos com tantos detalhes, e a calha constitui-se em um detalhamento não evidenciado.

A chuva foi um dos conteúdos representados tanto em situações de risco (47\% dos desenhos) quanto em situações de segurança ( $24 \%$ dos desenhos). A presença das bananeiras e rachaduras foi evidenciada principalmente em áreas com risco. Somente a EBM Enriche Klabunde não apresentou desenhos com bananeiras. Nos demais, a planta esteve bem difundida nos desenhos de todas as 
outras unidades escolares, associada às situações com risco.

Apesar de ser mencionado durante as aulas, nenhuma unidade escolar apresentou desenho com referências a entupimento de bueiros. Mesmo sendo um tema difundido na própria escola, a questão do lixo que pode ser transportado para um bueiro, obstruindo a passagem da água, não foi contemplada nos desenhos.

Dos sete conteúdos abordadas no terceiro encontro da Defesa Civil, todos foram representados nas áreas com risco, visto que se referem somente aos desastres. Em ordem decrescente, apareceram as variáveis danos materiais, danos ambientais, deslizamento de solo, casa caindo e inundação. Evidenciam-se os três desastres expressos pelos estudantes, destacando-se os deslizamentos, presentes em $15 \%$ de todos os desenhos analisados. Em termos numéricos, observaram-se, dos 197 desenhos, que somente três representaram furacões e oito apresentaram inundações (Figura 7).
Para a questão dos desastres, em especial os três eventos (furacão, deslizamento e inundação), realizando-se a análise estatística evidencia-se que existe diferença significativa entre os diferentes eventos representados nos desenhos ao nível de significância de 0,05 , com valor de $\mathrm{P}=0,001$ (Tabela 5).

Ao analisar a representação dos desastres por escola (Figura 8), nota-se que as unidades que destacaram os deslizamentos estão localizadas em uma região de revelo mais plano, não acidentado. Os desenhos da unidade escolar Professora Helena M. N. Winckler, situada em área de relevo acidentado, apresentaram a inundação como um desastre natural. Possivelmente, esse fator pode estar atrelado ao fato de que os desastres mais rotineiros para a população, como os deslizamentos para os habitantes de locais com relevo acidentados, podem ser esquecidos. Isso seria como um mecanismo de defesa ao risco. A população tende ou busca não perceber os riscos próximos ou mais recorrentes pa-

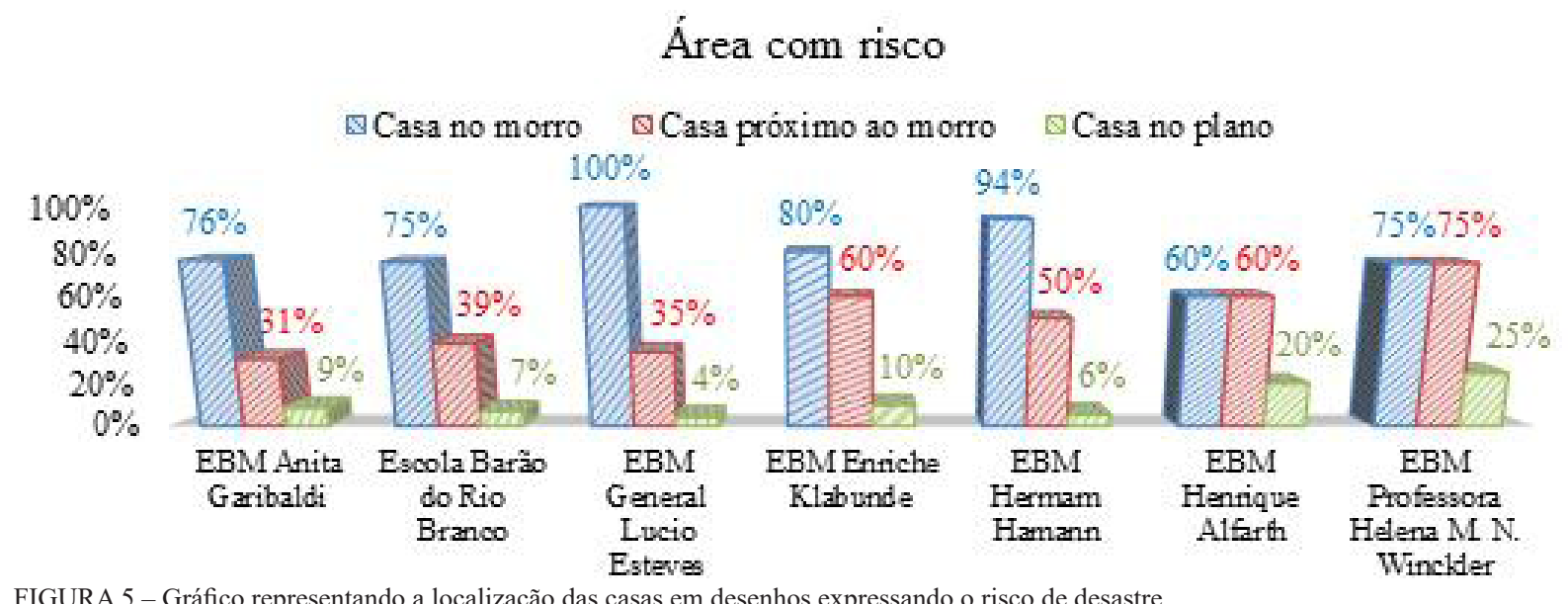

FIGURA 5 - Gráfico representando a localização das casas em desenhos expressando o risco de desastre 


\section{Área segura}

\section{$\bowtie$ Casa no morro $₫$ Casa próximo ao morro $₫$ Casa no plano}

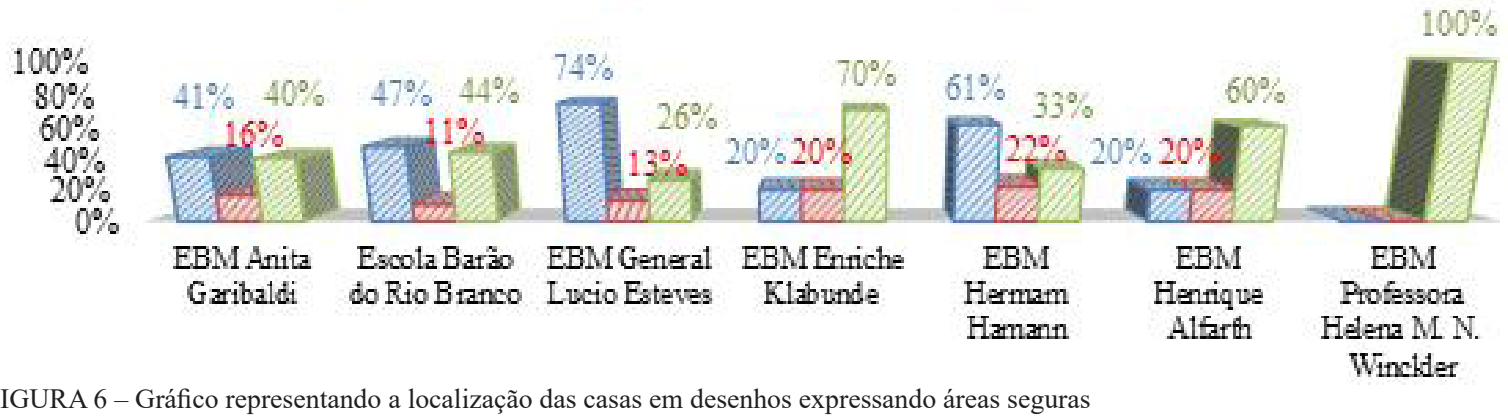

FIGURA 6 - Gráfico representando a localização das casas em desenhos expressando áreas seguras

\section{Desastres naturais}

« Deslizamento de solo Inundação « Furacão

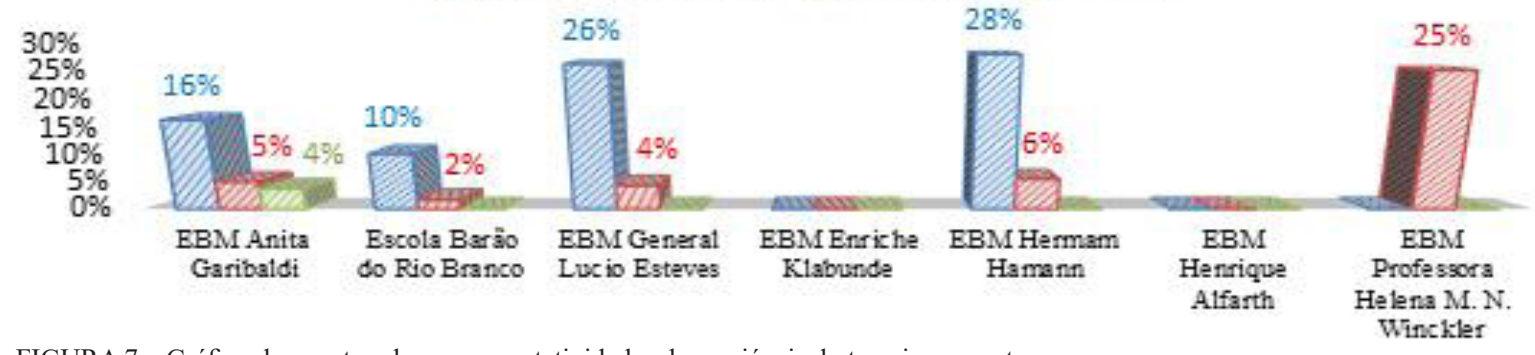

FIGURA 7 - Gráfico demonstrando a representatividades das variáveis do terceiro encontro

\section{Desastres naturais}

« Deslizamento de solo $₫$ Inundação « Furacão

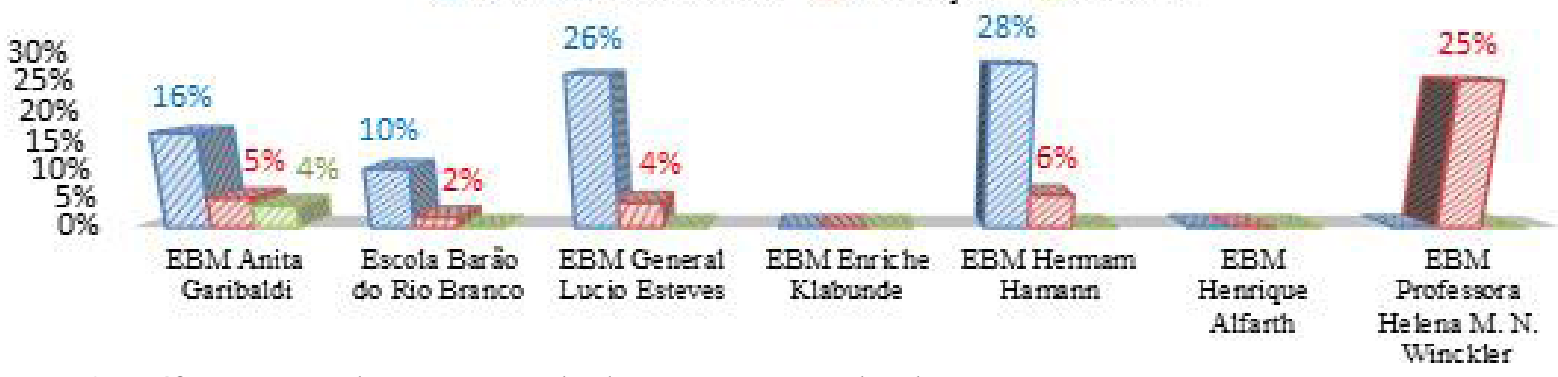

FIGURA 8 - Gráfico representando a porcentagem dos desastres presente nos desenhos 
ra se sentir mais confortável e segura em sua localidade. Para Burton \& Kates (1972), a possibilidade de negação do risco de desastre é maior quanto mais próximos os moradores estiverem dele.

TABELA 5 - Frequências absoluta e relativa entre: 1 - Inundação; 2 - Deslizamento e 3 - Furacão

\begin{tabular}{cccc}
\hline \multirow{2}{*}{ Categorias } & \multicolumn{2}{c}{ Frequências } & Qui-Quadrado \\
\cline { 2 - 4 } & Absoluta (N) & Relativa (\%) & (p-valor) \\
\hline 1 & 8 & 19,51 & $<0,001$ \\
2 & 30 & 73,17 & \\
3 & 3 & 7,32 & \\
Total & 41 & 100 & \\
\hline
\end{tabular}

Os deslizamentos foram os desastres naturais mais representados nos desenhos. Isso se justifica pela frequente evidência desses eventos no município e por serem muito destacados durante os encontros da Defesa Civil, visto que são rápidos e requerem agilidade de resposta, evitando-se perdas.

De acordo com Wechsler \& Schelini (2002), a representação gráfica de pensamentos e sentimentos apresentados por meio de desenhos é estabelecida como uma das formas de comunicação mais antigas da humanidade. As primeiras marcas e os feitos dos seres humanos foram desenhos nas cavernas, buscando registrar a sua história para os descendentes.

Para Menezes et al. (2008), o desenho tem sido uma ferramenta que permite à criança organizar informações, descrever experiências vividas e pensadas, incentivando-a a desenvolver um estilo de representação única sobre o mundo. Da mesma maneira, durante o desenvolvimento infantil, o desenho torna-se a primeira forma de expressão que criança consegue dominar, antes da leitura ou da escrita (Wechsler \& Schelini, 2002).
De acordo com Pavan (2009), incorporar os estudantes nas práticas da redução dos riscos de desastres, por meio de atividades que estimulem seu interesse pelo tema, subsidia para que os estudantes se sintam dispostos a identificar os possíveis riscos e implementar medidas de proteção civil. Esse processo pode ser abrangido como uma forma de avaliação que permite realizar a comparação entre um e outro objeto, caracterizando-se em uma mensuração, buscando representar a validade entre o fenômeno e os pressupostos do uso da linguagem (Menezes et al., 2008).

Para Pavan (2009), a aplicação de conteúdos relacionados ao tema dos desastres deveria ser uma preocupação pública, buscando disponibilizar esse conhecimento formal às crianças, auxiliando-as a organizar cognitivamente seus interesses, temores ou vivências relacionadas aos desastres. De fato, ao analisar os desenhos realizados após as atividades práticas educacionais, propostas pelas agentes civis de Blumenau, foi possível observar que os encontros oportunizaram informações aos estudantes, possibilitando-os observar de forma mais cautelosa os principais riscos que os envolvem. De acordo com o mesmo autor, no caso de pesquisas com crianças, utilizar a comunicação mediante expressões gráficas demostra-se um instrumento eficaz, podendo contribuir para a análise dos problemas sociais a serem enfrentados pela população, em situações de extrema vulnerabilidade.

Com relação aos encontros e seus conteúdos, nota-se que existe menor representatividade das variáveis abordadas do primeiro encontro. Isso pode estar relacionado com o distanciamento na escala temporal que cada encontro possui. Em média, os estudantes desenvolvem o desenho 15 dias após o primeiro encontro. Essa pode ser uma das conse- 
quências desse intervalo de tempo, entre o primeiro encontro e a elaboração do desenho.

A presença do grande número de desenhos associados com os deslizamentos tende a estar atrelada ao enfoque dado pela Defesa Civil a respeito desse evento, bem como à vivência dos próprios estudantes. O último evento de grandes precipitações registrado em Blumenau, durante o ano de 2015, causou um grande deslizamento, que foi divulgado pela mídia durante semanas.

Um ponto que merece destaque e deve ser abordado com os estudantes refere-se à variável chuva. A Defesa Civil Municipal de Blumenau deve interagir com os estudantes, a fim de promover outra visão sobre a precipitação, em que a água não é o problema ou o agente causador do desastre, mas constitui-se somente em seu elemento deflagrador. Vários desenhos relacionaram a água com algo ruim, diferenciando área seguras e inseguras com a ausência e presença da chuva, respectivamente.

Somado a isso, está o impacto causado por uma simples animação visual, que pode ser um vídeo, ou uma videoaula, cuja assimilação foi identificada nos desenhos. Uma das variáveis de maior representatividade nos desenhos foi a gramínea vetiver, abordada em um vídeo veiculado pela Defesa Civil como um dos conteúdos abordados no segundo encontro nas escolas. Esse vídeo, com apenas 10 minutos, no qual é realizada uma breve contextualização do potencial da planta, foi o necessário para que os estudantes usassem como base a situação dos personagens apresentados na pequena animação, evidenciando isso em seus desenhos. De acordo com Rosa (2000), alguns efeitos ou determinados exemplos são mais bem observados, ou somente podem ser observados se utilizadas técnicas como as gravações.
De acordo com Oliveira \& Dias (2012), recursos tecnológicos como vídeos, computadores e a própria internet ocasionam grandes impactos na educação, enfatizando a necessidade de que os professores e as escolas busquem se adaptar a estas novas tecnologias. Nesse sentido, sugere-se a utilização de videoaulas nos encontros futuros a serem realizados nas próximas escolas. Tais instrumentos de ensino-aprendizagem já foram roteirizadas, gravadas e editadas, com base em uma ação de um projeto de extensão do qual participam dois dos presentes autores. Tais videoaulas estão disponibilizados nos links $<$ https://youtu.be/2J185JrhO64> e $<$ https://youtu.be/WvkkQTxeveI $>$.

\section{Considerações finais}

Com este estudo, torna-se evidente que as práticas educacionais que contemplam a educação ambiental são propensas a mediar novos conhecimentos sobre o ambiente para os estudantes. Correlacionar a educação com a proteção civil dos cidadãos propicia a comunidade uma valorosa formação buscando prevenir os desastres naturais, na construção de uma cidade resiliente.

Apesar de haver certas alterações nos padrões dos desenhos, a análise estatística confirma que algumas variáveis foram mais evidenciadas nas representações dos estudantes, como as construções na parte superior dos morros, caracterizando-se como situações de riscos. Isso é relevante quando consideramos que muitos dos estudantes de Blumenau moram em áreas de morro.

Por outro lado, evidenciou-se a falta de relação com os demais desastres presentes no município de Blumenau, especialmente com as inundações. Em 
praticamente todos os desenhos, a situação mais comum estava relacionada com as movimentações gravitacionais de solo (deslizamentos). Isso indica a necessidade de reforçar a abordagem dos demais desastres naturais durante as práticas educacionais empregadas pela Defesa Civil.

Descobrir quais conteúdos foram mais empregados pelos estudantes em suas representações proporciona à equipe da Defesa Civil o desenvolvimento de novas abordagens metodológicas a serem empregadas nas escolas, bem como favorece o descobrimento de quais conteúdos e conceitos precisam ser ampliados. A sistematização dos "produtos finais", os desenhos do Projeto Defesa Civil na Escola, possibilitou um caráter científico à ação de educação ambiental desse órgão.

Nas investigações em educação ambiental, há ainda uma lacuna nos processos de avaliação das ações e políticas ambientais. Nessa direção, o conhecimento elaborado por meio desta pesquisa, mesmo que localmente, pode contribuir para futuros estudos, em outros contextos, que têm como objeto de investigação as interfaces da educação ambiental, os desastres ambientais e as cidades.

\section{Referências}

Alertablu - Enchentes registradas. 2015. Disponível em: http://alertablu.cob.sc.gov.br/p/enchentes

Appolinário, F. Dicionário de metodologia cientifica: um guia para a produção do conhecimento científico. São Paulo, Atlas, 2009.

Blumenau. Lei complementar n. ${ }^{\circ} 870$, de 01 de janeiro de 2013. Estabelece nova estrutura administrativa do poder executivo municipal de Blumenau e dá outras providências. Blumenau, 2013. Disponível em: http://leismunicipa.is/ifcen
Brasil. Os diferentes matizes da educação ambiental no Brasil. 1997-2007 2 Ed. Brasília/DF: Ministro do meio ambiente. Texto: SiviaCzapski, 2009. Disponível em: http://www.mma.gov.br/estruturas/educamb/_arquivos/ dif_matizes.pdf

Brasil. Lei n. ${ }^{\circ} 12.608,10$ de abril de 2012. Institui a Política Nacional de Proteção e Defesa Civil. Brasília: DOU de 11.4.2012. Disponível em: http://www.planalto.gov.br/ ccivil_03/_ato2011-2014/2012/lei/112608.htm

Brasil. Ministério da Integração Nacional. Construindo Cidades Resilientes. 20/05/2015. Disponível em: http:// mi.gov.br/cidades-resilientes

Brasil. Conselho Nacional de Educação. Resolução n. ${ }^{\circ} 2$ de 2012. Diretrizes Curriculares Nacionais para a Educação Ambiental, Brasília, DF, p. 1-7, 15 de junho de 2012. Disponível em: http://portal.mec.gov.br/index.php?option=com_docman\&view=download\&alias=10988-rcp002-12-pdf\&category_slug $=$ maio-2012-pdf\&Itemid $=30192$

Burton, I; Kates, R.W. The perception of natural hazards in resource management. In: English, P. W.; Mayfield, R. C. (Ed.). Man, Space and Environment. New York: Oxford University Press, 1972. p. 282-304.

CEPED; UFSC - Centro Universitário de Estudos e Pesquisas sobre Desastres. Redução de riscos de desastres nas escolas. Texto Sarah Marcela Chinchilla Cartagena. Florianópolis: CEPED/UFSC, 2012. Disponível em: <http:// www.cemaden.gov.br/pluviometros/arquivos/cartilhas/ reducao_de_riscos_de_desastres_nas_escolas_0.pdf

CEPED; UFSC - Centro Universitário de Estudos e Pesquisas sobre Desastres. Atlas brasileiro de desastres naturais 1991 a 2012: volume Brasil. Florianópolis: CEPED/UFSC, 2013. Disponível em: http://150.162.127.14:8080/atlas/ Brasil\%20Rev\%202.pdf

Clebsch, A. B.; Mors, P. M. Explorando recursos simples de informática e audiovisuais: Uma experiência no ensino de Fluidos. Revista Brasileira de Ensino de Física, 26(4), 323-333, 2004. Disponível em: http://www.scielo.br/pdf/ rbef/v26n4/a06v26n4.pdf

Comitê do Itajaí. Plano de recursos hídricos da bacia do Itajaí: Documento sintese. Blumenau: Fundação Agência de Água do Vale do Itajaí, 2010. Disponí- 
vel em: http://189.73.116.32/xmlui/bitstream/handle/123456789/702/Documento_sintese.pdf?sequence $=1$

EIRD ONU. Estratégia Internacional para a Redução de Desastres das Nações Unidas. Marco de Ação de Hyogo 2005-2015: Aumento da resiliência das nações e das comunidades frente aos desastres. Versão resumida. Genebra, Suíça, 2007. Disponível em:http://www.defesacivil.pr.gov.br/ arquivos/File/Marco/MarcodeHyogoPortugues20052015. pdf

Frank, B.; Kobiyama, M.; Tachini, M. Descrição do desastre: as enxurradas. In: Frank, B.; Sevegnani, L.; Tomaselli, C. C. (Org.), Desastre de 2008 no Vale do Itajaí: água, gente e política. Blumenau: Agência de Água do Vale do Itajaí, 2009. p. 94-101. Disponível em: http://189.73.116.32/ xmlui/bitstream/handle/123456789/710/cap08-livroDesastre2008noVI_med.pdf?sequence $=8$

Guivant, J. S. A trajetória das análises de risco: da periferia ao centro da teoria social. Cadernos de Pesquisa, 46, 3-38, 1998.

Hein, N.; Kroenke, A.; Rodrigues, J. M. M. Modelagem matemática e tragédias naturais - sobre a avaliação de materiais de (re)construção em Blumenau-SC. In: Congresso Internacional de Ensino de Matemática. Canoas, 16 de out., 2013. Disponível em: http://www.conferencias.ulbra.br/ index.php/ciem/vi/paper/view/1440

IBGE. Sinopse do censo demográfico de Santa Catarina. 2010. Disponível em: http:/www.censo2010.ibge.gov.br/ sinopse/index.php?uf $=42 \&$ dados $=04202402010$

Jacobi, P. R. Educação ambiental: o desafio da construção de um pensamento crítico, complexo e reflexivo. Educação e Pesquisa, 31(2), 233-250, 2005. Disponível em: http:// www.scielo.br/pdf/ep/v31n2/a07v31n2.pdf

Marques, M. L. A. P.; Silva, A. F.; Araújo, J. E. Q.; Queiroz, T. H. S.; Almeida, I. D. A.; Marinho, A. A. A educação ambiental na formação da consciência ecológica. Ciências Exatas e Tecnológicas, 1(1), 11-18, 2014. Disponível em: https:// periodicos.set.edu.br/index.php/fitsexatas/article/download $/ 1336 / 753$

Medeiros, A. B.; Mendonça, M. J. S. L.; Sousa, G. L.; Oliveira, I. P. Importância da educação ambiental na escola nas séries iniciais. Revista Faculdade Montes Belos, 4(1),
1-17, 2011.

Menezes, M.; More, C. L. O. O.; Cruz, R. M. O desenho como instrumento de medida de processos psicológicos em crianças hospitalizadas. Avaliação Psicológica, 7(2), 189-198, 2008. Disponível em: http://pepsic.bvsalud.org/scielo.php?script=s ci arttext\&pid=S1677=04712008000200010-\&lng=pt\&nrmisso

Moura, R.; Silva, L. A. D. A. E. Desastres naturais ou negligência humana? Revista Geografar, 3(1), 58-72, 2008. Disponível em: http://ojs.c3sl.ufpr.br/ojs/index.php/ geografar/article/view/12910

Narváez, L.; Lavell, A.; Ortega, G. P. La gestión del riesgo de desastres: um enfoque basado em procesos. Secretaría General de la Comunidad Andina, Lima, 2009.

Oliveira, N. M. D.; Dias Junior, W. O uso do vídeo como ferramenta de ensino aplicada em biologia celular. Enciclopédia Biosfera, 8(14), 1788-1809, 2012.

ONU - Organizações das Nações Unidas. Como construir cidades mais resilientes - Um guia para gestores públicos locais: Uma contribuição à Campanha Global 2010-2015 - Construindo Cidades Resilientes - Minha Cidade está se preparando! Genebra, Novembre de 2012. Disponível em: http://www.unisdr.org/files/26462_guiagestorespublicosweb.pdf

Pavan, B. J. C. O olhar da criança sobre o desastre: uma análise baseada em desenhos. In: Valencio, N.; Siena, M.; Marchezini, V.; Gonçalves, J.C. (Orgs.). Sociologia dos desastres: construção, interfaces e perspectivas no Brasil. São Carlos: Rima Editora, 2009. p. 96-106.

Pian, L. F. D.; Alves, D. Desafios da divulgação científica em cobertura jornalística de desastre ambiental. Ciência e Educação,19(4), 929-946, 2013. Disponível em: http://www.scielo.br/scielo.php?pi$\mathrm{d}=\mathrm{S} 1516-73132013000400010 \& \mathrm{script}=\mathrm{sci}$ _artt ext

Pinheiro, A.; Severo, D. L. Análise do Evento Pluviométrico Catastrófico de Novembro de 2008 na Região de Blumenau, SC. In: Congresso brasileiro de meteorologia, 16., 2010, Belém. Anais... Belém: CBMET. 1:1-11, 2010. Disponível em: http://cbmet2010.web437.uni5.net/anais/ 
artigos/408_76562.pdf

Renn, O. The role of risk perception for risk management. Reliability Engineering and System Safety, 59, 49-62, 1998. doi: 10.1016/S0951-8320 (97) 00119-1

Renn, O. Risk governance: coping with uncertainty in a complex world. London: Earthscan, 2008. doi: 10.1007/978-1-4020-6799-0

Rodrigues, T. As estratégias internacionais de recuperação de desastres. Territorium, 17, 223-227, 2010. Disponível em: http://www.uc.pt/fluc/nicif/riscos/Documentacao/Territorium/T17_artg/24Territorium_223-227.pdf

Rosa, P. R. S. O uso dos recursos audiovisuais e o ensino de ciências. Caderno Brasileiro de Ensino de Física, 17(1), 33-49, 2000. Disponível em: https://periodicos.ufsc.br/ index.php/fisica/article/view/6784/6249

Santos, J. F. A. A redução de vulnerabilidades como estratégia no enfrentamento de desastres. Razón y Palabra, 19(91),7-23, 2015.

Silva, T. D. da. Educação Ambiental: a educação para o consumo na sociedade da informação. Linguagem em Discurso, 11(3), 563-584, 2011. Disponível em: http://www. scielo.br/pdf/ld/v11n3/a06v11n3.pdf

Tachini, M.; Kobyiama, M.; Loesch, C.; Severo, D. L.; Santos, H. Avaliação de danos de inundações ocorridas em Blumenau/SC nos anos 1983, 1984, 1992 e 2001. In: XVIII Simpósio Brasileiro de Recursos Hídricos. 2009.

Tominaga, L. D.; Santoro, J.; Amaral, R. (Org). Desastres naturais conhecer para prevenir. 1.ed. São Paulo: Instituto Geológico, 2009 Disponível em: http://www.igeologico. sp.gov.br/downloads/livros/DesastresNaturais.pdf
UNESCO. Redução do risco de desastres nos currículos escolares: estudos de casos de trinta países. France, p. 218, 2012. Disponível em: http://unesdoc.unesco.org/images/ 0022/002205/220517por.pdf

UFPA. Qui Quadrado, 2011. Disponível em: http://www. ufpa.br/dicas/biome/bioqui.htm

UNISDR. Implementation of the international strategy for disaster reduction. United Nations, General Assembly 3 September 2014. Disponível em: http://www.preventionweb.net/files/resolutions/N1452549.pdf

UNISDR. United Nations International Strategy for Disaster Reduction. Sendai Framework for Disaster Risk Reduction 2015-2030. UN world conference on disaster risk reduction, 2015.March 14-18, Sendai, Japan. Geneva: United Nations Office for Disaster Risk Reduction; 2015a. Disponível em: http://www.preventionweb.net/files/43291_sendaiframeworkfordrren.pdf

UNISDR. Briefing note on the 21st Conference of the Parties to the UNFCCC (COP21) in Paris. United Nations Office for Disaster Risk Reduction (UNISDR), 2015b. Disponível em: https://www.unisdr.org/we/inform/publications/46311

Wechsler, S. M.; Schelini, P. W. Validade do Desenho da Figura Humana para avaliação cognitiva infantil. Avaliação Psicológica, 1(1), 29-38, 2002. Disponível em: http:// pepsic.bvsalud.org/scielo.php?script=sci_arttext\&pi$\mathrm{d}=\mathrm{S} 1677-04712002000100004 \& \operatorname{lng}=\mathrm{pt} \& \mathrm{nrm}=\mathrm{iso}$ 